\title{
Perancangan Robot Lengan Pemindah Barang Berdasarkan Ukuran Berbasis Arduino Dengan Sensor Ping Hc-Sr04 Dan Sensor Inframerah
}

\author{
Deny Hasminta Sembiring Maha ${ }^{1}$, Yudiranda Dizky Thantowi S ${ }^{2}$, Candra Adi Saputra Tamba ${ }^{3}$ \\ 1,2,3 Universitas Prima Indonesia /Fakultas Teknologi dan Ilmu Komputer \\ Jl. Sekip Simp. Sikambing. Medan Indonesia \\ e-mail: *1 dennyhasminta@gmail.com,2yudiranda23@gmail.com, ${ }^{3}$ candrasaputraadi24@gmail.com
}

\begin{abstract}
Abstrak
Saat ini perkembangan teknologi sangatlah canggih, maju dan menarik, perkembangan teknologi dibidang elektronika, Iot, dan robotika. Oleh karena itu, sebagian perusahaan telah menggunakan sistem robotika untuk membantu pekerjaan serta meningkatkan hasil produksi. Proses pemindahan barang serta perhitungan jumlah barang di industri masih banyak yang menggunakan sistem manual sehingga menyebabkan proses ini tidak akan efektif dan akan banyak memerlukan waktu serta tenaga manusia. Oleh sebab itu, penelitian ini bertujuan untuk membuat robot lengan otomatis, dilengkapi dengan mikrokontroler, actuator, sensor Ping HC-SR04, sensor inframerah, LCD 16x2, dan catu daya dalam memindahkan barang dan menghitungnya. Robot lengan yang dirancang dapat bergerak untuk melakukan pengambilan barang dan pemindahan barang ke masing-masing wadah berdasarkan ukurannya dan menghitung jumlah barang yang ada di dalam wadah tersebut. Hasil pembacaan ukuran barang dan perhitungan barang akan di tampilkan pada LCD 16x2. Ukuran barang yang akan dideteksi tinggi $7 \mathrm{~cm}, 5 \mathrm{~cm}, 4 \mathrm{~cm}$ dan lebar $5 \mathrm{~cm}, 4 \mathrm{~cm}$ dan $3 \mathrm{~cm}$.
\end{abstract}

Kata kunci: Robot lengan, Ukuran, Perhitungan barang

\begin{abstract}
Currently, technological progress in the fields of electronics, IoT, and robotics are very sophisticated, advanced and interesting. Some companies recently have used robotics systems to help at work and to increase production results. Many of the process of moving goods and the calculation of the number of goods in the industry still uses a manual system, therefore the process abovementioned will not be highly effective and will require a lot of time and manpower. Therefore, this research aims to make an automatic arm robot, equipped with a microcontroller, actuator, Ping HC-SR04 sensor, infrared sensor, 16x2 LCD, and power supply in order to make process of moving and calculating goods. The arm robot is designed to be able to move to take goods and move goods to each container based on its size, and to calculate the number of items in the container. The output of the reading of the size of the goods and the calculation of the goods will be displayed on the 16x2 $L C D$. The size of the item to be detected is $7 \mathrm{~cm}, 5 \mathrm{~cm}, 4 \mathrm{~cm}$ in height and $5 \mathrm{~cm}, 4 \mathrm{~cm}$ and $3 \mathrm{~cm}$ in width.
\end{abstract}

Keywords : robot arm, size, calculation of goods

\section{PENDAHULUAN}

Saat ini perkembangan teknologi sangatlah canggih, maju dan menarik, perkembangan teknologi dibidang elektronika, Iot, dan robotika. Otomasi telah menjadi inti dari seluruh perusahaan manufaktur modern, banyak perusahaan mengotomasi kegiatan mereka untuk suatu alasan yaitu meningkatkan hasil produktifitas dan mengurangi bahaya akibat kelalaian manusia.

Otomasi telah mengubah sesuatu yang sebelumnya manual menjadi otomatis. Misalnya seperti penyortir, pemindah barang, penghitung jumlah barang dan lain sebagainya. Ada berbagai jenis alat 
pemindah barang yang kita jumpai di industri yaitu robot lengan, forklift, dan conveyor belt. Lengan robot digunakan untuk membantu mempermudah pekerjaan manusia melakukan tugas tertentu dan yang berbahaya bagi manusia (Muhammad Hadi Maftuh, 2020).

Perkembangan teknologi robotika saat ini diperlukan dalam berbagai bidang kehidupan. Penggunaan teknologi robotika ini bertujuan agar mempermudah kegiatan manusia, meringankan tugas-tugas yang memiliki resiko tinggi. Salah satu kegiatan yang dapat dilakukan oleh robot lengan yaitu proses pemindahan barang atau objek dari satu tempat ke tempat yang lain. Pada proses pemindahan barang yang dilakukan secara manual oleh manusia akan mempertimbangkan beberapa faktor yaitu berat barang, jarak perpindahan dan tenaga manusia yang dibutuhkan. Semakin berat dan semakin banyak barang, atau semakin jauh jarak perpindahan yang akan dilakukan, maka tenaga manusia yang dibutuhkan untuk melakukan proses pemindahan barang akan semakin besar. Selain itu, ketidakmungkinan tenaga manusia dapat bekerja selama 24 jam juga merupakan faktor utama yang mempengaruhi tingkat efektifitas serta kualitas kegiatan sehingga target produksi tidak dapat tercapai dengan baik. Untuk itu maka dibutuhkan sebuah robot lengan yang dapat melakukan proses kegiatan tersebut sehingga diharapkan mampu mempermudah proses pemindahan barang serta meningkatkan tingkat efektifitas yang baik dalam hal waktu, tenaga, maupun hasil kualitas produksi(Rimas, O., dkk, 2018).

Adapun tujuan dari penelitian ini adalah untuk membuat sebuah alat yaitu robot lengan pintar berbasis Arduino yang mampu bekerja secara otomatis memindahkan barang dan diletakan ke dalam wadah berdasarkan ukuran menggunakan sensor ping HC-SR04 sebagai sensor pengidentifikasi ukuran dan sensor inframerah sebagai sensor pengidentifikasi untuk mengetahui jumlah barang yang ada pada masing-masing wadah secara realtime.

Adapun manfaat dari penelitian ini adalah :

a. Sebagai alat bantu memudahkan pekerjaan manusia baik individu maupun khususnya pada industri-industri skala besar baik dari segi efesiensi waktu, tenaga, kualitas serta hasil produksi yang diperolehi.

b. Sebagai penelitian awal pengenalan ukuran benda dengan menggunakan dua buah sensor dengan robot lengan sebagai pengangkat benda serta menempatkannya pada masing-masing wadah berdasarkan ukuran, dan dua buah sensor inframerah sebagai pengidentifikasi jumlah barang yang ada pada masing-masing wadah

Penulis menetepkan beberapa batasan masalah pada perancangan ini yaitu:

a. Bagaimana merancang dan membuat robot lengan pemindah dan pemilah barang.

b. Bagaimana robot lengan pemindah barang dapat menemukan titik ukuran barang dengan menggunakan sensor ping HC-SR04 dan sensor inframerah sebagai pengidentifikasi jumlah barang tersebut.

c. Masukan berupa 3 barang yaitu : kotak dengan ukuran masing-masing yaitu ketinggian berkisar $7 \mathrm{Cm}, 5 \mathrm{Cm}, 4 \mathrm{Cm}$ dan lebarnya berkisar $5 \mathrm{Cm}$, dan $4 \mathrm{Cm}, 3 \mathrm{Cm}$.

d. Outputnya dalam bentuk wadah yang memiliki 3 wadah dengan masing-masing wadah telah ditentukan untuk ukuran dari barang yang akan diletakkan ke masing-masing wadah tersebut.

e. Menggunakan motor servo sebanyak 6 buah untuk menggerakan masing-masing lengan.

f. Terdapat sebuah LCD 16x2 sebagai penampil ukuran barang dan jumlah barang.

g. Komunikasi antara laptop dengan ATmega328 menggunakan komunikasi serial USART yang dihubungkan dengan modul yang sudah tersedia dipasaran yaitu modul USB to TTL converter.

\subsection{Robot Lengan}

\section{STUDI PUSTAKA}

Robot lengan (arm robot) adalah robot mekanik yang dirancang menyerupai gerakan lengan manusia dan dapat melakukan tugas fisik baik menggunakan pengawasan dan control manusia atau bahkan terotomatisasi dengan program yang telah dibuat.Robot lengan mempunyai beberapa sendi diantaranya adalah bahu (shoulder), siku (elbow), pergelangan (wrist), dan pencengkram (gripper). Robot lengan juga harus memiliki komponen-komponen pendukung sebagai bagian dari pembentuknya diantaranya ada aktuator dan kontroler(Cempaka F., dkk, 2016). 


\subsection{Motor Servo}

Motor servo adalah sebuah perangkat atau aktuator yang dirancang khusus dengan sistem umpan balik close loop, motor servo terdiri dari sebuah motor serangkain gear, rangkain pengendali(controller), dan potensiometer sehingga dapat diatur posisi sudut dari poros output motor. Serangkain gear yang ada pada poros motor dc akan memperlambat putaran poros dan meningkatkan torsi motor servo tersebut. Potensiometer berfungsi sebagai pengatur batas untuk menentukan batas sudut dari putaran servo(Cempaka F., dkk, 2016).

\subsection{Sensor inframerah}

Sensor inframerah adalah sebuah komponen elektronika yang di dalamnya terdapat transmitter dan receiver yang dapat mendeteksi benda ketika cahaya inframerah terhalangi oleh benda(Muhammad, A. J., dkk, 2020).

\subsection{Sensor Jarak(Ping HC-SR04)}

Sensor jarak adalah sebuah sensor yang mampu mendeteksi adanya keberadaan objek di depannya tanpa kontak fisik dengan berkisar antara $1 \mathrm{~cm}-3 \mathrm{~m}$. sensor ultrasonik mendeteksi objek dengan cara mengirimkan gelombang ultrasonic dan kemudian menerima pantulan gelombang tersebut dan kemudian menghitung waktu antara pengiriman sinyal dan penerimaan sinyal untuk menentukan jarak objek yang terdeteksi(Hadijaya, P., dkk, 2012).

\subsection{Arduino Uno}

Arduino Uno adalah sebuah papan Mikrokontroler yang bersifat sumber terbuka(open source), didalamnya terkoneksi mikroprosesor memori, port I/O dan peripheral lainnya. Arduino memiliki 14 pin digital Input/Output dan 6 pin Input analog PWM. Arduino juga memiliki input catu daya sebesar 12 volt dan memiliki tegangan output sebesar 5 volt(Ulinnuha, L., dkk, 2018).

\subsection{Catu daya(Power supply)}

Catu daya(power suplly) adalah sebuah peralatan listrik yang didalamnya memiliki rangkain elektronika untuk mengubah tegangan ac menjadi tegangan dc. Catu daya berperan untuk menyediakan energi listrik dan mengolahnya sebagai sumber tegangan pada perangkat elektronika.

\subsection{Module Stepdown LM259S}

Module stepdown ini berfungsi sebagai penurun tegangan dapat digunakan sebagai solusi pada masalah perbedaan sumber tegangan dari objek sederhana. Module stepdown ini dapat menurunkan tegangan tinggi dc menjadi tegangan rendah dc, sehingga dapat menghasilkan tegangan yang dapat disesuaikan untuk keperluan sumber tegangan elektronik.

\subsection{LCD dan I2C}

LCD adalah kepanjangan dari Liquid Crystal Display merupakan jenis penampil untuk menampilkan data yang berupa tulisan seperti angka, huruf atau karakter tertentu. Sedangkan, I2C yaitu integrated circuit adalah komunikasi serial dua arah yang didesain khusus untuk mengirim dan menerima data.

\subsection{Sistem kerja robot dengan sensor}

Robot lengan merupakan bagian dari beberapa segmen sendi dan dilengkapi dengan aktuator agar dapat menggerakan setiap sendi sesuai dengan kebutuhan dengan sistem kerja sebagai pengangkat material, pengelasan dan lainnya sebagai. otomatisasi robot lengan meliputi sistem kendali cerdas yang memiliki sensor sebagai indra agar dapat memerintahkan robot untuk melakukan tugas fisik yang telah ditentukan. Misalnya pada robot lengan pengangkat barang sensor akan mendeteksi keberadaan objek kemudian mengola perintah yang telah di program kemudian robot lengan akan bergerak otomatis mengambil objek tersebut dan menempatkannya ke tempat yang telah di tentukan, kemudian robot akan kembali ke posisi semula sampai menunggu perintah atau sampai sensor kembali mendeteksi keberadaan objek. 


\section{METODE PENELITIAN}

\subsection{Jenis Penelitian}

Jenis penelitian yang digunakan dalam kasus ini adalah jenis penelitian True Experimental. Penelitian jenis eksperimen ini adalah penelitian yang dilakukan untuk mengetahaui dan mencari bagaimana suatu variabel tertentu berpengaruh terhadap variabel lain di dalam suatu kondisi yang terkontrol secara berurut dan sistematis.

\subsection{Prosedur penelitian}

Adapun prosedur penelitian yang dilakukan di dalam pelaksanaan penelitian ini adalah sebagai berikut:

1. Tahap persiapan. Aktifitas penelitian ini mengenai tentang persiapan bahan dan alat yang dibutuhkan dalam melaksanakan penelitian.

2. Tahap perancangan. Tahap ini dilakukan untuk merancang sistem meliputi:

a) Robot lengan pemindah dan pemilah barang

b) Robot lengan pemindah dan pemilah barang

c) Pengenalan barang dengan mengetahui ukuran barang tersebut

d) Perhitungan barang dan

e) Analisa pengujian

3. Tahap implementasi dan pengujian. Tahap ini dimaksudkan sebagai langkah pengujian dari kinerja system

4. Tahap penyelesain. Tahap ini dimaksudkan sebagai catatan kegiatan dan hasil penelitian didokumentasikan.

Bagan alir tahapan penelitian ditunjukkan pada gambar di bawah sebagai berikut:

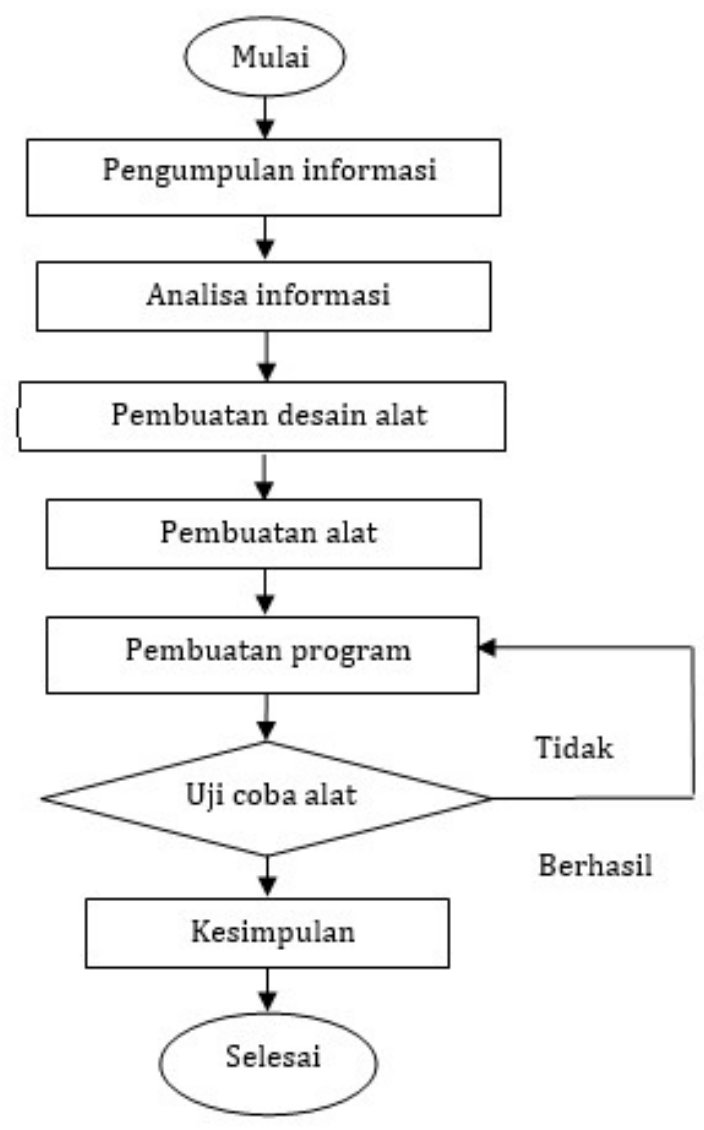

Gambar 1 Metode Penelitian 


\subsection{Perancangan Robot Lengan dengan Sensor HC-SR04 dan Sensor inframerah}

Pergerakan robot lengan pemindah barang berdasarkan ukuran ini memilki lima bagian utama yang akan digerakkan dengan motor servo. Bagian yang berperan sebagai penggerak atau sendi oleh Gerakan motor servo disebut link.

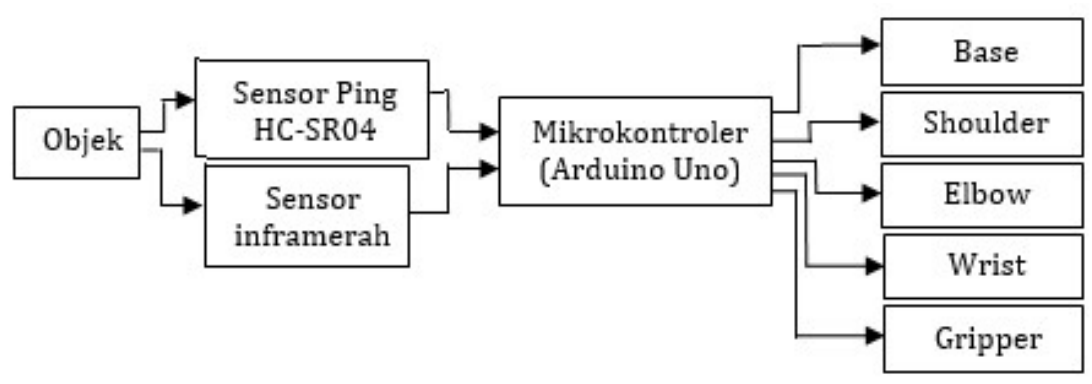

Gambar 2 Perancangan Robot Lengan

Gambar 3.2 berikut ini memperlihatkan desain perancangan mekanik lengan robot pemindah barang berdasarkan ukuran dengan lima bagian utama diantaranya

1. Bagian dasar/bawah(base)

2. Bagian bahu(shoulder)

3. Bagian siku (elbow)

4. Bagian pergelangan(wrist)

5. Bagian pencengkram(gripper)

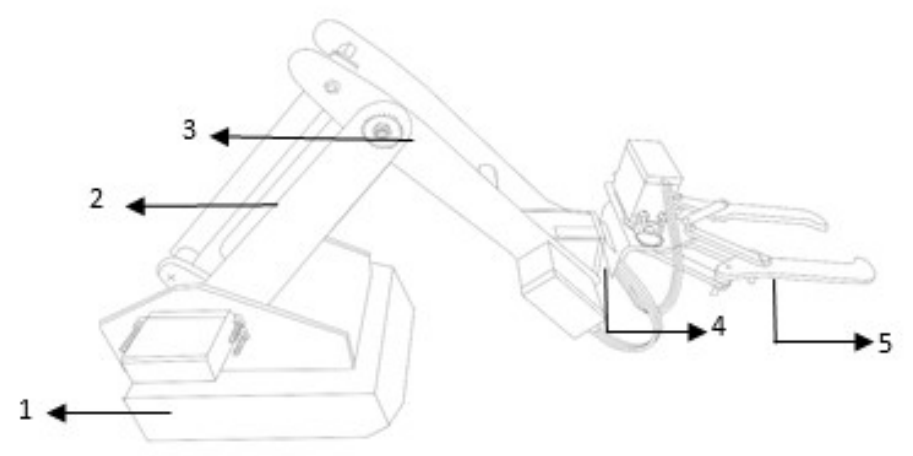

Gambar 3 Desain Lengan Robot

Tabel 1 memperlihatkan dimensi Panjang setiap penghubung untuk base, shoulder, elbow, wrist, dan gripper dalam perancangan desain lengan robot.

Tabel 1 Panjang Setiap Penghubung

\begin{tabular}{|c|c|c|}
\hline No & Penghubung & Panjang penghubung \\
\hline 1 & Base & $13 \mathrm{~cm}$ \\
\hline 2 & Shoulder & $18 \mathrm{~cm}$ \\
\hline 3 & Elbow & $20 \mathrm{~cm}$ \\
\hline 4 & Wrist & $6 \mathrm{~cm}$ \\
\hline 5 & Gripper & $14 \mathrm{~cm}$ \\
\hline
\end{tabular}


Gambar 3 memperlihatkan area kerja fisik robot lengan pemindah barang berdasarkan ukuran.

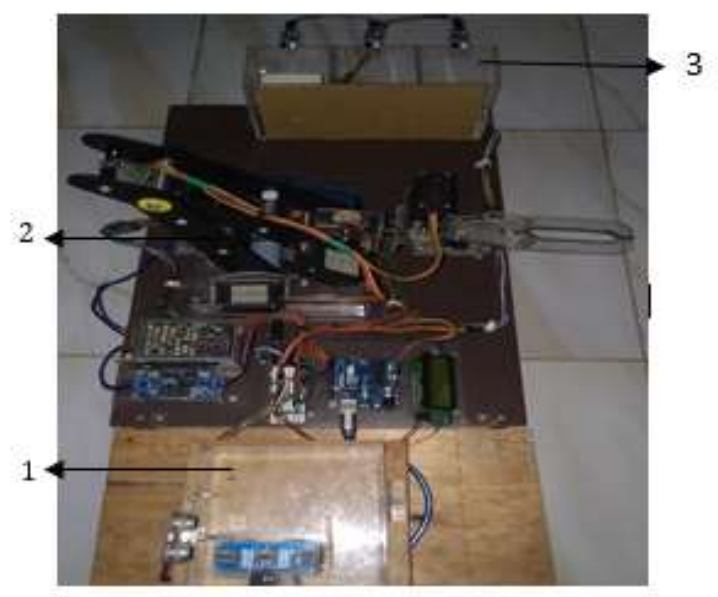

Gambar 4 Area kerja robot lengan

Tabel 2 menjelaskan area kerja robot lengan yang ditunjukkan angka 1,2, dan 2 pada Gambar 3.

Tabel 3 Area kerja robot lengan

\begin{tabular}{|l|l|}
\hline No & \multicolumn{1}{|c|}{ Keterangan } \\
\hline 1 & Area tempat objek yang akan mendeteksi ukuran barang \\
\hline 2 & Robot lengan \\
\hline 3 & Tempat masing-masing barang sesuai ukurannya \\
\hline
\end{tabular}

\section{HASIL DAN PEMBAHASAN}

Dalam penelitian ini Sensor ping $h c$-sr04 digunakan sebagai sensor untuk mendeteksi keberadaan barang yang ada di depannya dan mengukur tinggi dan lebar dari barang tersebut dan sensor ini juga inti utama untuk mengerakan robot lengan untuk mengambil barang tersebut. jika sensor ping HC-SR04 tidak mendeteksi keberadaan barang maka robot lengan tidak akan bekerja atau pada posisi yang telah ditentukan. dan sensor inframerah akan bekerja Ketika robot lengan bekerja mengambil barang dan menempatkan barang tersebut ke tempat yang ditentukan maka sensor inframerah akan menghitung jumlah barang yang ada pada tempat yang telah ditentukan.

Pengujian ini dilakukan bertujuan supaya mengetahui apakah sensor Ping HC-SR04 yang mendeteksi(mengukur) objek sesuai dengan tinggi benda dapat bekerja sesuai yang diharapkan. Pengujian yang dilakukan pada penelitian ini sebanyak 7 kali dengan ukuran benda yang sama. persamaan yang digunakan untuk mencari nilai error tersebut :

$$
\frac{x-y}{y} x 100
$$

Erorr $\%=$

dimana $\mathrm{x}$ : nilai rata-pengujian

$\mathrm{y}:$ nilai sebenarnya 
Tabel 4. Tabel pengujian sensor ping hc-sr04 mendeteksi lebar benda

\begin{tabular}{|c|c|c|c|c|c|c|c|c|c|c|}
\hline \multirow{2}{*}{ No } & \multirow{2}{*}{$\begin{array}{l}\text { Tinggi } \\
\text { barang }\end{array}$} & \multicolumn{7}{|c|}{ Sensor Ping hc-sr04 } & \multirow{2}{*}{$\begin{array}{c}\text { Rata - } \\
\text { rata } \\
(\mathrm{x})\end{array}$} & \multirow{2}{*}{$\begin{array}{l}\text { Tingkat } \\
\text { erorr } \%\end{array}$} \\
\hline & & Uji 1 & Uji 2 & Uji 3 & Uji 4 & Uji 5 & Uji 6 & Uji 7 & & \\
\hline 1 & $7 \mathrm{~cm}$ & $7 \mathrm{~cm}$ & $6 \mathrm{~cm}$ & $7 \mathrm{~cm}$ & $6 \mathrm{~cm}$ & $7 \mathrm{~cm}$ & $6 \mathrm{~cm}$ & $7 \mathrm{~cm}$ & 6,5 & $-7,1 \%$ \\
\hline 2 & $5 \mathrm{~cm}$ & $5 \mathrm{~cm}$ & $5 \mathrm{~cm}$ & $5 \mathrm{~cm}$ & $6 \mathrm{~cm}$ & $5 \mathrm{~cm}$ & $5 \mathrm{~cm}$ & $5 \mathrm{~cm}$ & 5,1 & $2 \%$ \\
\hline 3 & $4 \mathrm{~cm}$ & $4 \mathrm{~cm}$ & $4 \mathrm{~cm}$ & $5 \mathrm{~cm}$ & $4 \mathrm{~cm}$ & $5 \mathrm{~cm}$ & $4 \mathrm{~cm}$ & $4 \mathrm{~cm}$ & 4,2 & $5 \%$ \\
\hline
\end{tabular}

Pengujian ini dilakukan bertujuan supaya mengetahui apakah sensor Ping HC-SR04 yang mendeteksi (mengukur) objek sesuai dengan lebar benda dapat bekerja sesuai yang diharapkan. Pengujian yang dilakukan pada penelitian ini sebanyak 7 kali dengan ukuran benda yang sama. Tabel 1 dan Tabel 4.2 memperlihatkan hasil nilai rata-rata dan tingkat error dari 7 kali pengujian dengan sensor ping HC-SR04 dalam mendeteksi ketinggian dan lebar benda.

Tabel 5. Tabel pengujian sensor ping hc-sr04 mendeteksi lebar benda

\begin{tabular}{|c|c|c|c|c|c|c|c|c|c|c|}
\hline \multirow{2}{*}{ No } & \multirow{5}{*}{$\begin{array}{c}\text { Lebar } \\
\text { barang }\end{array}$} & \multicolumn{5}{|c|}{ Sensor Ping hc-sr04 } & \multirow{2}{\text{Rata}-}{$\begin{array}{c}\text { Tingka } \\
\text { rata } \\
\text { (x) }\end{array}$} & $\begin{array}{c}\text { t erorr } \\
\%\end{array}$ \\
\hline 1 & $5 \mathrm{~cm}$ & $\begin{array}{c}5 \\
\mathrm{~cm}\end{array}$ & $4 \mathrm{~cm}$ & $5 \mathrm{~cm}$ & $5 \mathrm{~cm}$ & $5 \mathrm{~cm}$ & $5 \mathrm{~cm}$ & $4 \mathrm{~cm}$ & 4,7 & $-4,2 \%$ \\
\hline 2 & $4 \mathrm{~cm}$ & $\begin{array}{c}4 \\
\mathrm{~cm}\end{array}$ & $4 \mathrm{~cm}$ & $3 \mathrm{~cm}$ & $4 \mathrm{~cm}$ & $3 \mathrm{~cm}$ & $4 \mathrm{~cm}$ & $4 \mathrm{~cm}$ & 3,7 & $-7,5 \%$ \\
\hline 3 & $3 \mathrm{~cm}$ & $\begin{array}{c}3 \\
\mathrm{~cm}\end{array}$ & $4 \mathrm{~cm}$ & $3 \mathrm{~cm}$ & $2 \mathrm{~cm}$ & $2 \mathrm{~cm}$ & $3 \mathrm{~cm}$ & $3 \mathrm{~cm}$ & 2,8 & $-6,6 \%$ \\
\hline
\end{tabular}

Pengujian ini dilakukan bertujuan supaya mengetahui apakah sensor inframerah dapat mendeteksi keberadaan barang serta menghitung barang tersebut. Tabel 3 memperlihatkan hasil nilai rata-rata dan tingkat error dari 7 kali pengujian dengan sensor inframerah.

Tabel 6 Tabel pengujian sensor inframerah

\begin{tabular}{|c|c|c|r|r|r|r|r|c|}
\hline \multirow{2}{*}{ No } & \multirow{2}{*}{$\begin{array}{c}\text { Tinggi } \\
\text { barang }\end{array}$} & \multirow{2}{*}{$\begin{array}{c}\text { Lebar } \\
\text { barang }\end{array}$} & \multicolumn{5}{|c|}{ Sensor inframerah } & \multirow{2}{*}{ Hasil } \\
\cline { 5 - 8 } & & & Uji 1 & Uji 2 & Uji 3 & Uji 4 & Uji 5 & \\
\hline 1 & 7 & 5 & $\checkmark$ & $\checkmark$ & $\checkmark$ & $\checkmark$ & $\checkmark$ & Berhasil \\
\hline 2 & 5 & 4 & $\checkmark$ & $\checkmark$ & $\checkmark$ & $\checkmark$ & $\checkmark$ & Berhasil \\
\hline 3 & 4 & 3 & $\checkmark$ & $\checkmark$ & $\checkmark$ & $\checkmark$ & $\checkmark$ & Berhasil \\
\hline
\end{tabular}

Gambar 4.1 memperlihatkan pengujian mengangkat barang. pengujian ini dilakukan untuk mengetahui apakah robot lengan dapat mengambil barang dengan ukuran yang sudah di tentukan dan menjepit barang serta menempatkannya ke dalam wadah yang ditentukan. 


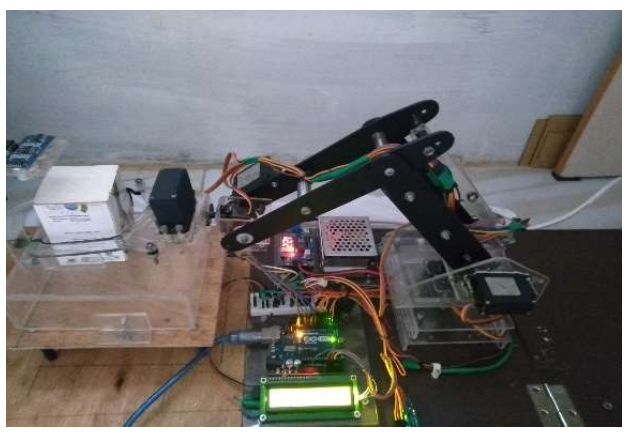

Gambar 5 Pengujian Mengambil barang

Gambar 5 memperlihatkan pengujian meletakan barang kedalam wadah. Pengujian ini dilakukan untuk mengetahui apakah robot lengan mampu melettakan barang sesuai dengan ukurannya.

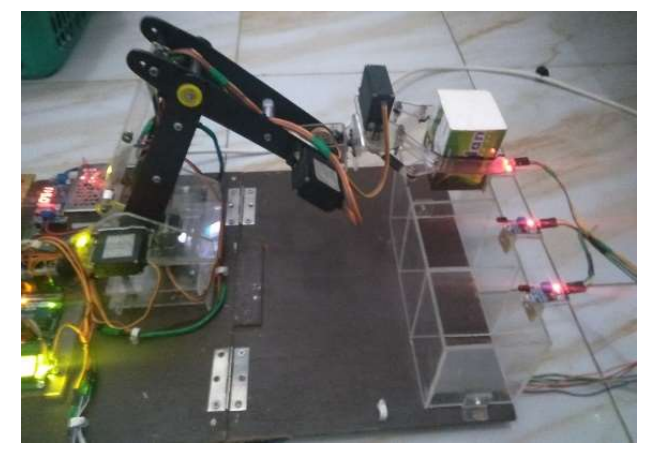

Gambar 6 Pengujian meletakan barang

\section{a. Sistem Kerja keseluruhan alat}

Saat barang tidak terdeteksi oleh sensor ping HC-SR04 maka robot lengan akan ada pada posisi yang sudah di tentukan, dan LCD 16x2 akan menampilkan karakter "Tidak Ada Barang Yang Terdeteksi". Saat barang diletakan pada area sensor yang telah ditentukan maka sensor akan membaca ukuran barang tersebut dan menampilkan hasil baca sensor yang mendeteksi barang tersebut ke LCD 16x2, kemudian robot lengan akan bergerak mengambil barang tersebut dan menjepit barang dan bergerak menuju tempat yang telah ditentukan berdasarkan ukurannya. Saat robot lengan sampai pada tempat peletakan barang maka sensor inframerah akan mendeteksi dan menghitung jumlah barang yang telah diletakan kedalam wadah tersebut.

\section{KESIMPULAN}

Setelah melakukan penelitian dan pengamatan pada sistem kerja robot lengan, maka dapat diketahui hasil pengerjaan dan pengamatannya. Alat yang telah dibuat dapat bekerja untuk mengambil barang sesuai dengan ukurannya dan meletakan ke tempat yang telah ditentukan. Sistem pemindahan barang dan penghitungan barang ini dibuat secara otomatis dengan 2 sensor ping hcsr04 dan 3 sensor inframerah pada masing-masing wadah.

Hasil pengukuran barang yang terdeteksi oleh sensor ping $h c-s r 04$ akan ditampilkan pada LCD 16x2 dan hasil perhitungan barang juga akan di tampilkan pada LCD 16x2. Robot lengan 
mampu mengambil barang dengan tinggi yang terdeteksi $7 \mathrm{~cm}, 5 \mathrm{~cm}, 4 \mathrm{~cm}$ dan lebar yang terdeteksi $5 \mathrm{~cm}, 4 \mathrm{~cm}$, dan $3 \mathrm{~cm}$ dan menempatkannya pada masing-masing wadah sesuai ukuran barang tersebut.

\section{DAFTAR PUSTAKA}

[1] Anugrah, A. \& Putra, Jaya. (2019). Perancangan Dan Pembuatan Sistem Kendali Kipas Angin Otomatis Berbasis Mikrokontroler ATMega32, voteTEKNIKA, 7 (2): 1-7.

[2] Cempaka, F., Abdul, Muid. \& Ikwhan, R. (2016). Rancang Bangun Lengan Robot Sebagai Alat Pemindah Barang Berdasarkan Warna Menggunakan Sensor Fotodioda, coding jurnal komputer dan aplikasi, 4.

[3] Hadijaya, P. Erik, H. \& Tjetje, G. (2012). Akuisi Data Kinerja Sensor Ultrasonik Berbasis Sistem Komunikasi Serial Menggunakan Mikrokontroler ATMega 32, electrans, 11 (2): 3643.

[4] Hendra, Jaya. (2016). Desain Dan Implementasi Sistem Robotika Berbasis Mikrokontroller. Makasar : Edukasi Mitra Grafika.

[5] Hari, Santoso. (2015). “Arduino Untuk Pemula”, E-book : 2015

[6] Julien, Bayle. (2013). C Programming For Arduino. Birmingham : Packt Publishing.

[7] Muhammad, A., J. Sumarno. Jalaluddin. Dedy, H. \& Ika, O.,K. (2020). Perancangan Dan Implementasi Alat Penghitung Roti Otomatis Menggunakan Arduino Uno dan Module Sensor Infrared, Jurnal Media Informatika Budidarma. 4 (1): 172-177.

[8] Muhammad, H., M. (2020). Lengan Robot Pemindah Barang Berdaasarkan Ukuran Tinggi, Electronica and Elektrical Journal of Innovation Technology, 1 (2): 36-41.

[9] Rimas, O. Rizal, M. \& Gembong, Edi., S. (2018). Implementasi Robot Lengan Pemindah Barang 3 Dof Menggunakan Metode Inverse Kinemetics, jurnal pengembangan teknologi informasi dan ilmu komputer, 2

[10] Syukranullah. Bukhari. \& Ismi, A. (2019). Rancangan Bangun Robot Lengan Berbasis Mikrokontroler Arduino Uno, Jurnal Mesin Sains Terapan, 3 (1): 7-10.

[11] Ulinnuha, L. \& Joko, S., S. (2018). Perancangan Robot Arm Gripper Berbasis Arduino Uno Menggunakan Antarmuka Labview, Barometer, 3 (2): 138-141.

[12] Widodo, Budiharto. (2006). Belajar Sendiri Membuat Robot Cerdas. Jakarta : PT Elex Media Komputindo. 